\title{
AN INTERVENTION PROGRAM ON BLOOD PROTOZOA ACQUIRED BY NEEDLE STICK INJURY AND INFECTION CONTROL
} By

\author{
AMR M. EL-SAYED ABDEL-MOTAGALY ${ }^{1}$, ABEER MOHAMMAD \\ ABDALLAH IBRAHIM ${ }^{1}$ and TOSSON A. MORSY ${ }^{2}$ \\ Military Medical Academy ${ }^{1}$, Cairo 11291 and Faculty of Medicine ${ }^{2}$, \\ Ain Shams University, Cairo 11566, Egypt
}

\begin{abstract}
Needle stick injuries are a common event in the healthcare environment. When drawing blood, administering an intramuscular or intravenous drug, or performing other procedures involving sharps, needle can slip and injure the healthcare worker. This allows for transmission of pathogens. Injuries also occur during needle recapping or failure to place used needles in the sharps containers. Also, lack of access to or failure to use appropriate personal protective equipment can cause needle stick injuries. Night shifts also put practitioners at risk for needle stick injuries. The study assessed the effect of an intervention program for nursing staff knowledge, performance and attitude related to blood protozoa acquired by needle stick injury. Design an interventional study (pre-post study) was used for 90 nursing staff, ten of them pilot study were excluded. The study tools composed of educational needs assessment tool, knowledge questionnaire sheet (pre/post-test), observation check list and attitude Results showed significant improvements in nursing staff knowledge, performance and attitude.
\end{abstract}

Keywords: Nurses, Intervention, Blood protozoa, Needle stick injury, Infection control

\section{Introduction}

The accidental puncture of the skin by a needle during a medical intervention, percutaneous piercing wound caused by a sharp instrument Commonly encountered by people handling needles in the medical setting, such injuries are an occupational hazard for health care professionals. Law enforcement personnel are also at high risk for needle stick injuries at work. Despite their seriousness, half of all needle stick injuries went unreported. As needle stick was recognized as occupational hazards, prevention became the regulations subject (NOSH, 2012).

During surgery, a needle or other sharp instrument may inadvertently penetrate the glove and skin of the surgeon or other operating room personnel. Injuries may occur when needles are passed between personnel, when personnel load needles into a needle driver, when personnel place needles in an overfilled or poorly located sharps container, or tie off sutures while still connected to the needle. Generally needle stick injuries cause only minor bleeding or visible trauma, however, even in the absence of bleeding the risk of viral infection remains. Scalpel injuries tend to be larger than a needle stick. In turn, needle stick injury may also pose a risk for a patient if the injured health professional has a blood borne illness (Ker et al, 2010).

Blood borne protozoa can be found in the bloodstream of infected patients and spread to health care workers (HCW) through exposure to infected blood (by blood transfusion or by sharing needles or contaminated syringes). Blood protozoa encountered in Egypt are babesiosis, leishmaniasis, malaria, and toxoplasmosis (Saleh et al, 2017). Many blood-borne protozoa are spread by insectvectors but toxoplasmosis is not so (CDC, 2014).

Nurses thought a little needle pricking might be a carrier of one of many transferred diseases. It increases among nurses who are too busy to take a routine blood samples to make sure her blood is clean. Visual information ensured more awareness between working nurses and interactive workshops. Particular steps, from handling needle, recapping needle, pulling needle to air discharging, are all necessary to be the cautiously treated by every nurse staff (Thomas and Murray, 2009). Behavior of recapping needles persists despite the well documented 
dangers and international recommendations against this practice. Also, there were deficits in knowledge, and practice of simple protective measures as wearing gloves, not removing needles with hand before disposal, and using disposal containers (CDC, 2008).

Practice among nurses about post occupational exposure to blood and body fluids is inadequate. Knowing the infectious-disease status of the source patient, as well as understanding the risks of transmission, might make nurses more adherent to infectiousdiseases prescriptions (Baudu, 2011). Nurses must allow the wound to bleed freely, and immediately reporting blood exposure is a must, but, many exposures were not reported (Shiva et al, 2011). The sharps injuries pose a serious threat to health professionals, patients, and downstream workers. Medical sharp means object or instrument used for carrying out activities to healthcare and able to cause injury by means of cutting or piercing skin injury including infection (Adams et al, 2013). Safer sharp is a medical sharp designed and constructed to incorporate a feature or mechanism that prevents or minimizes the risk of accidental injury from cutting or piercing skin (Statutory Instrument, 2013). Every percutaneous needle stick and sharps injury carries a risk of infective blood borne pathogens. Yet, these exposures often are considered a part of their job. Health care workers (HCWs) mainly were exposed to these pathogens via contaminated needlestick and sharps injuries. Omar et al. (2015) in Kuwait studied the prevalence of incident occupational exposure to blood and other infectious materials among HCWs during 2010 and evaluated the factors associated with such incidents. They concluded that the needle stick injuries were the most common exposure among them, and nurses were the most frequently involved HCP category. A good proportion of exposures could be easily prevented. HBV vaccination coverage is incomplete. Health-care associated infection (HAIs) were defined as those who developed during hospitalization but were neither present nor incubated upon the patients admission to the hospital; generally for those infections that occur more than $48-72$ hours after admission and within ten days after discharge (Collins, 2008). Health-care associated infection was a major problem in developed countries (5\% to $10 \%$ ) of hospitalized patients, but in developing countries exceeded 25\% (Grayson, 2009). Risk of HAI depended on the factors related to infectious agent (e.g. virulence, capacity to survive indoors, antimicrobial resistance); the host (e.g. advanced age, low birth weight, underlying diseases, state of debilitation, immune suppression, malnutrition) and the environment (e.g. prolonged hospitalization, invasive devices and procedures, antimicrobial therapy). HCWs can also become infected during patient care (WHO, 2009). The infection control team is responsible for the dayto-day activities of the infection control program. Health care establishments must have access to specialists in infection control, epidemiology, and infection disease, including physicians and infection control practitioners. In some countries, the professionals are specialized; and may be administratively a part of another unit (e.g. a microbiology laboratory, medical or nursing administration, public health services). The reporting structure must ensure the infection control team has appropriate authority to manage an effective infection control program. In large facilities, this will usually mean a direct relationship with senior administration (CDC, 2006). Nurses, who are frequently the first contact a patient has with the health care system, may find themselves identifying the presence of infectious diseases, tracking and identifying cases, notifying the proper authorities and implementing disease containment programs. In remaining vigilant for the presence of a new disease, the individual nurse functions as a 'mini-surveillance system.' In fact, an astute clinician is a critical component of any national surveillance system. The first lines of detection of a biologic agent released into population reside with a 
physician or nurse who diagnoses an individual with signs and symptoms of biologic agent (Pyrek et al, 2001).

\section{Subjects and Methods}

Significance: All nursing staff is the front line of health care team who face patients, so, early detection and rapid reporting which considered from nursing "golden responsibilities" and utmost important for taking the decision for isolation, treatment and disease spread prevention. In general, there is a lack of knowledge among the nursing staff and infection control nurses about blood parasites acquired by needled stick injury, although there was $(74.9 \%)$ of injured health care workers (HCWs) had appropriate immediate care (Hsieh et al, 2006).

Consequently, a tailored educational program would help in improving nursing staff knowledge and attitude related to blood protozoa acquired by needle-stick injury to improve the care quality, and to acquaint the Egyptian Nursing Staff especially those who share in the Peace Keeping Forces Mission to endemic areas with such fatal diseases. The four blood infectious protozoa were selected based on epidemiological importance. These were malaria, babesiosis, toxoplasmosis and visceral leishmaniasis (Morsy, 2013; El-Bahnasawy et al, 2010; 2011).

This study assessed the effect of an intervention program for knowledge and attitude regarding blood parasites acquired by needle stick injury in a fever hospital as compared to a general one via by assessing knowledge related blood protozoa acquired by needle stick injury; and attitude related to safety measures in handling and disposal of sharps instruments.

The specific role of the individual nurse will probably be determined by place of employment and the health care needs of the population of patients being seen. However, all nurses should be familiar will the fundamental concepts of epidemiology, early detection, and surveillance, and appreciate the role of the nurse in contributing to the success of this system. Even nurses who do not work in situations directly related to public health should appreciate that they may be contributing to surveillance data collection systems. Each time a nurse enters a patient variable into emergency department records or electronic medical records (EMRs), that data may be used for surveillance purposes. The following section provides an overview of basic concepts of epidemiology, early detection and surveillance (Guerra et al, 2010), infection control proved a necessary component of safe, high quality patient care and is essential for the well-being of the patient and of the staff. The fundamentals of infection control are applicable across all setting where health care is being provided worldwide. These fundamentals need to be employed regardless of constraints in resources and support, as they are designed to protect the patient and provider against exposure to infectious microorganisms and against the morbidity and mortality associated with these agents should infection occur (WHO, 2006). Each level of the infection control program, from person charged with administrative support to the direct care provider at the patient bedside, should share in covering all the responsibility of the infection control (MOHP, 2004). The importance of infection prevention has been recognized as far back as biblical times, and it is still important in the early years of the twenty-first century, Infection control began when leper colonies were separated from the rest of the population by using an unclean bell. The bell was also used during the 1665 plague endemic to warn people to stay away when the dead bodies of plague victims were collected at night, in order to avoid contact with healthy people. In 1665, protective clothing, masks and gloves were used by doctors in order to prevent cross-contamination of plague. Later, in the early 1800 s, records show that the mothers of babies delivered by doctors and medical students were dying from infections. After that, Hungarian obstetrician, to prevent infection and death rates declined immediately. Florence Nightingale was the 
first nurse on record who attempted to prevent infection during her work in the Crimean War. She recognized that placing a large number of patients in a limited space might contribute to the spread of infection. She also introduced many hygiene protocols, some of which remain relevant to this day. A new year in infection management began with the advent of penicillin in the 1940s, and infection prevention measures were established in the late 1950s due to a pandemic of infections from S. aureus (Perry, 2007). Sharps injuries can occur in any healthcare setting, including non-hospital settings such as in office based practices, home health care and long term care facilities (ASCC, 2008). The Health Protection Agency (2008) stated that: the greatest source of infection was percutaneous exposure to patients with HCV (84\% between 2000-2007); and relative risks of exposure following percutaneous injury, especially from deep penetrating injury involving a hollow-bore needle or one visibly contaminated with blood was $1: 3$ for HBV, 1:30 for HCV \& 1:300 for HIV (Knot, 2010). In developing regions, $40 \%-65 \%$ of $\mathrm{HBV} \& \mathrm{HCV}$ infections HCWs were due to percutaneous occupational exposure (Hanafi et al, 2011). The renewed interest in parasitic diseases in the United States markedly increased numbers of clinical and research laboratories have the potential for exposure to parasites and risk for acquiring parasitic infections. Herwaldt and Juranek (1993) among technicians focused on malaria, leishmaniasis, toxoplasmosis and trypanosomiasis (American \& African types), which are severe, even fatal, and difficult to diagnose. Al-Saigul et al. (2000) in Saudi Arabia reported a girl who developed $P$. falciparum in a non-malarious area. Twelve to 18 days before onset, she had been hospitalized for asthma on the same ward as three malaria patients. The only link between the malaria patients and the asthma patient was a multidose heparin container used to fill syringes for use on heparin locks and intravenous devices. Contamination of heparin with blood occurred on at least one occasion when a needle had been left in place through the septum of this container and was used to refill a used syringe. National Surveillance System for HCWs showed that nurses sustain highest number of percutaneous injuries. But, physicians, technicians, laboratory staff, and support personnel housekeeping staff are also at risk. Hollow-bore needles are responsible for $56 \%$ of all sharps injuries, occurred when use a sharp device on a patient, after use and before disposal of a sharp device and during or after appropriate or inappropriate disposal of sharp devices (CDC, 2008). Even persons who are experts on parasitic diseases often do not know what clinical manifestations to expect when natural modes of transmission are bypassed, how to monitor for infection after accidental exposures, and whether to begin the presumptive antimicrobial therapy before infection is documented (Galazzi et al, 2014). Sharps must not be passed directly from hand to hand and handling should be kept to minimum. Needles must not be recapped, bent or broken after use. After they are used, singleuse syringes and needles, scalpel blades and other sharp items should be placed in an appropriate container. These containers should be clearly labeled, puncture and leak proof, and. The containers should be located at the point of use or, if this is not possible, as close as practical to the use area. Reusable sharps requiring transport to a reprocessing area must be placed in a puncture-resistant lidded container (CDC, 2003). Many accidental needle stick occur when staff recaps needles. Recapping is a dangerous practice: If at all possible, dispose of needles immediately without recapping them. If it is necessary to recap a needle don't bend or break it or remove syringe by hand (Goodall, 2007). Immediate action if a sharp injury is sustained to reduce the risk of infection sharp are Seek care immediately if you sustain a sharps injury; if skin is penetrated, wash the affected area immediately with soap and water. Ethanol-based hand rub can be used to 
clean the area if soap and water are not available; Do not squeeze the affected area; Report the incident immediately to your supervisor; Ask about follow-up care, including post-exposure prophylaxis (INOHSC, 2010). Implementation of patient care practices for infection control is the role of the nursing staff. Nurses should be familiar with practices to prevent occurrence and spread infection, and maintain appropriate practices for patients during the hospital stay (WHO, 2002). The senior nurse administrator is responsible for participating in the infection control committee promoting the development and improvement of nursing techniques, and ongoing review of aseptic nursing policies, with approval by the infection control committee. The responsibilities also involve developing training programs for members of the nursing staff. The implementation of techniques, for the prevention of infections in specialized areas such as the operating suite, the intensive care unit, the maternity unit and newborns, and monitoring of nursing adherence to policies (Burke et al, 2007). The nurse in charge of a ward is responsible for maintaining hygiene, consistent with hospital policies and good nursing practice on the ward monitoring aseptic techniques including hand washing and use of isolation, reporting promptly to the attending physician any advance of infection in patients under the nurses care, and initiating patients isolation and order culture specimens from any patient showing signs of a communicable disease, when the physician is not immediately available she/he is also responsible for limiting patient exposure to infections from visitors, hospital stuff, other patients, or equipment used for diagnosis or treatment, drugs and patient care-supplies (Taylor et al, 2001). The nurse in charge of infection control must identify nosocomial infections, invested infection type; infective organism, and share in training of personnel. Infection control nurse should receive training in basic infection control and have frequent communication with the infection con- trol practitioner (Anderson et al, 2006) Her/ His roles also involve surveillance of hospital infections participation in outbreak investigation development of infection control policy and review and approval of patient care policies relevant to infection control. She/he is also responsible for ensuring compliance with local and national regulation, and acting as a liaison with public health and with other facilities where appropriate, providing expert consultative advice to staff health and other appropriate hospital programs in matters relating to transmission of infections (Dawson, 2003). Job or taskspecific education and training on preventing transmission of infection agent associated with healthcare during orientation to the healthcare facility are essential. Information must be updated periodically during ongoing education programs. All healthcare personnel must be targeted for education and training. Including but not limited to medical, nursing, clinical technicians, laboratory staff and property service (house-keeping), laundry. Maintenance and dietary workers; students, contract staff and volunteers (lau et al, 2004), managers should ensure implementation of infection control measures and incorporate preventing transmission of infectious agents into the objectives of the hospitalized patients and occupational safety programs (Burke, 2003). They should prevent transmission of infectious agents a priority for the healthcare organization (McGowam and Tenover, 2004). The nurse manager should also involve infection control personnel in decisions on facility construction and design, determined need, and environmental assessments (Srinivasan et al, 2002). In all areas where health-care was delivered the necessary for the consistent observance of standard precautions, including hand hygiene products and personal protective equipment, e.g., gloves, gowns, face and eye protection (OSHA, 2001). Nurse must also develop and implement policies and procedures to ensure that reusable patient care equipment is cleaned and reprocessed ap- 
propriately before use on another patient, and for early detection and management of potentially infectious persons at initial point of patient encounter (Rutual and Weber, 2004). Also, nurse should identify performance indicators of the effectiveness of organization-specific measures to prevent infectious agents' transmission (standard and transmission-based precaution), establish processes to monitor adherence to those performance measures, providing feedback to staff members (Babcock et al, 2004). Infection control assistant helped hospital infection control team to identify, quantify, and control community-acquired infectious outbreaks, antibiotic resistance, and nosocomial infections by surveillance and analysis of patient data from electronic medical records, pharmacies, laboratories, admission/discharge/transfer records, and others (Theresa et al, 2013).

\section{Results and Discussion}

No doubt, educational programs can over light any health topic and bring it into focus in order to help nurses to face any needed action (Fey and Miltner, 2000). The present study was aimed to develop training program for nursing staff regarding infectious blood protozoa acquired by needle stick injury in Military Hospitals by assessing the level of nursing staff knowledge, performance and attitude, designing an educational training program based on identified training need, implementing and evaluating the effect of training program on nursing staff.

In order to design the educational program we have to identify weak and strong points of the related topics among the nursing staff that will be explored in this part. Furthermore the first step in planning any professional development assess the learning needs target group or individual to determine the structure of the program in terms of objectives, content, and activities, learning needs can be individual, organizational, or societal and must be clearly defined during the planning process (Lynor and Desilet, 2007).
Learning needs assessment has a fundamental role in education and training. Thus, learning needs assessment is crucial in the educational process (Grant, 2002) Also, learning needs analysis is a central component of continuing professional development but there is a lack of psychometrically developed learning needs assessment tools. Self-assessment questionnaires are emerging as a key method (While et al, 2007). This was in contradictory with training need assessment done by Itrat et al. (2009) prior to the educational program conducted in their interventional study as they reported that the most studied topic and the program was tailored and specific and they relayed that on national interest of that particular topic.

The present study showed that $(60 \%)$ of nurses at fever hospital and (70\%) at general hospital attended course of infection control. CCOHS (2005) reported that needle stick injuries are common hazard. Some hospitals report one third of nursing and laboratory staff suffer such injuries each year. Askarian et al. (2007) in Iran stated that nurses must attend courses on isolation and standard precaution as well as relayed on proper infection control committee acts and commitment and raised awareness of HCWs towards importance of training. Singru and Banerjee (2008) showed that needle-stick injuries and cuts were the common occupational accidents exposing HCWs to blood and body fluids. Soknes (2005) reported in 2001 reduced in NSIs exposure from $(52 \%)$ to only (28\%) due to good application of infection control. Vij et al. (2001) showed that highly educated nurses had higher knowledge regarding principles of infection control of blood parasites transmitted by blood transfusion or needle stick injury. Also, Molyneux (2003) found that the most of HCWs needed educational cession about malaria and blood parasites. But, Abd El Hamed et al. (2010) reported that the powerful motive for training in hospitals was promotion and obligation from the managers. 
The most of the nurses needed to know the role of nursing in application of infection control (90\%) at fever hospital and (68\%) at general hospital, which agreed with Frankel, (2008) who reported that nurse leaders must demonstrate resilience in responding to change and supporting others to embrace this in a positive way. Effective leaders should be capable of reframing the thinking of those whom they were leading, enable them to see changes not only imperative but, also achievable (Frankel, 2008). Dyson et al. (2009) showed in their study that education for nursing staff is not always systematically planned and developed and often relies on the interest area and assessment of nurse educators. Knowledge levels as regards studied topics throughout the program: Knowledge is valuable mainly to think in more profound ways, knowledge includes recall or recognition of facts, procedural patterns, and concepts that serve in the development of intellectual abilities and skills an intellectual skill is gained during a course of study that transferred to other situations (Sausa, 2006). Knowledge is acquired through formal and informal study in conjunction with experience in a specific domain of nursing practice (Considine et al. 2007).The present study agreed with Carmela et al. (2012) who found nurses training and knowledge are able to reduce the risk of accidents by exposure to biological agents. A study conducted on nurses in the United States showed low prevalence of training and high rate of underreporting of needle sticks and other exposure accidents 48.9\% (Gershon et al, 2007). Lipscomb et al. (2009) in USA stated that little was known about blood exposure risk among personnel providing care to the patients at home. They compared blood exposure risks among unlicensed home care personal care assistants (PCAs) and home care registered nurses (RNs). They concluded that PCAs were at increased risk of injury on doing nursing-related activities for which they were inexperienced or lack training. They added that it is a must to protect home
HCWs from blood exposure, mainly by assuring coverage \& enforcement of the occupational safety and health administration; blood-borne pathogen standard at: http:// www.osha.gov/pls/oshaweb/owadisp. show_document?

All nurses had knowledge about occupational exposure and importance of infection transmission. Ahmed et al. (2008) in Mansoura University Hospital reported that few nurses and laboratory technicians had less knowledge about blood-borne diseases and signs and symptoms. Alwutaib et al. (2012) in Kuwait found good knowledge level among nurses as modes of transmission diseases.

The dominance of malaria as the highest level of knowledge throughout the program may explain by that it is a very frequent topic in all nursing books in addition to resurgence of the disease and the international concern about it. Baird (2000) reported malaria as an infectious disease with nursing staff the highest concern. Krafts et al. (2011) recommended that all nursing staff especially at military hospitals should be aware of all related to malaria especially highly endemic areas and how to protect soldiers travel in missions as Peace Keeping Forces.

There were highly significant differences $(p<0.001)$ related to Babesia at pre, post and follow up phase. Also, a highly significant difference $(\mathrm{P}<0.001)$ related to infantile visceral leishmaniasis at pre, post \& follow up phase. This agreed with Ausburn (2004) who applied educational program on leishmaniasis types, prevention and treatment. But, Luz et al. (2005) reported that baseline knowledge possessed by registered nurses, students, and users of healthcare service confirmed previous studies. Questionby-question analysis showed that all participants (exception those of zoonosis control agents) had poor knowledge of leishmaniasis as to signs and symptoms.

All nurses had satisfactory knowledge level as regard toxoplasmosis with high significant differences $(\mathrm{p}<0.001)$, as compared 
with pre, post and follow up phase. Toxoplasmosis has significant impact not only on animal production but also on public health worldwide (Sudan et al, 2013). Kaye (2011) found it was important that nurses be aware of toxoplasmosis, recognize when it should be considered as a differential diagnosis, and understand how it is diagnosed and treated. The present study showed the median scores of nursing staff knowledge about infection control of four diseases through the program Pre, Post and follow up phase $(\mathrm{p}<0.001)$. Fey and Miltner (2000) reported that when the knowledge score of all participants improved after the program, implementation indicated that they were highly interested in the contents, and media and methods of teaching used were successful in stimulating their enthusiasm, Tweed and Tweed (2008) showed that complication of the educational program resulted in improved levels of knowledge. The present study showed that all nurses' knowledge scored regarding topics throughout the program. All nurses at the fever hospital were good in total knowledge at post-test. Those at the general hospital (98\%) were good in the total knowledge at post-test, highly difference $(\mathrm{P}<0.001)$ indicated significant improvement of knowledge in post-test as compared to pre-test. Cummingham (1998) reported difference between pre \& post-test of all nurses knowledge in educational program that indicated occurrence of learning on the same line. Dyson et al. (2009) reported that ongoing education for the nursing workforce is a must. The cost of education is high to the organization and the individual, and must therefore be cost-effective, relevant and appropriate. Military nursing staff performances to infection control measures: Actual performance of the nursing staff concerning hand hygiene; $93.3 \%$ had highest performance at pretest and $100 \%$ at post-test and follow up at fever hospital and at the general hospital $36 \%$ had perform proper hand washing technique at pre-test, due to inadequate knowledge, high work load, and increased to $88 \%$ at post-test and follow up. Pittet (2001) reported the factors influencing adherence by HCWs to hand washing procedures to barriers as skin irritation, interference with worker-patient relationship, patient needs perceived as a priority, insufficient time, and high workload and understaffing, lack of scientific information showing the impact of improved hand hygiene on hospital infection rates and ignorance of or disagreement with relevant guidelines and protocols. Currie et al. (2011) reported that perfect hand washing technique and commitment to hand wash criteria and guidelines as a good indicator of success of infection control committee and good program and supervision. Idang et al. (2014) stated that practice of hand washing proved the most effective means of preventing health care associated infections but poorly done. There were significant differences between pre; post and follow up related to hand hygiene. Regarding complete set of hand washing facilities, the present study showed that washing basin and good water supply were available but paper towel not available. This agreed with NHS surveillance (2010) reported that hand wash facility was available and enough but there were defect bio-waste management and facilities. CDC (2007) listed hindrances to noncompliance to hand washing included ineffective and in-adequate provision of water, lack of appropriate facilities and materials in health care setting. There were significant differences between pre, post \& follow up related to all items concerning personal protective equipment (PPE). In the present study, the gowns and gloves were enough but nurses said that the goggles and face shields were neither available nor enough, which indicated provision of goggles and face shields and also poor knowledge and attitude towards value of goggles and face shields. Kabbash et al. (2007) in Egypt reported that protocols for prevention, PPE measures and post exposure prophylaxis were mostly neither available or nor accessible in the studied units of hemodialysis. Singru and Banerjee, 
(2008) reported that shortage in provision of masks and gown was a great cause of skin blood exposure. Regarding gowns in the study showed that nurses at fever hospital $(80 \%)$ at pre-test increased to $(100 \%)$ and at general hospital (92\%) was HCP wear gown during procedures at the pre-test, which increased to $(96 \%)$ at post-test, they used the gowns and clothing during procedures or activities where contact with blood or body fluid. This agreed with Curtis (2008) study, where $76 \%$ of HCWs used gowns in patient care and agreed with Vaz et al. (2010) who reflected the positive role of infection control team in orientating newly joined staff about wearing of PPE, and thus reduced the risk of exposing skin or mucous membranes to potentially infectious materials. The present study showed that needles and syringes were used only for one patient at the two hospitals, but the worst (70\%) at fever hospital and $(76 \%)$ at general hospital pre-test were disinfection of the rubber septum on a medication vial with alcohol prior to piercing, might be due to inadequate knowledge about safety injection, absence of guidelines or instructions and supervision lack. Alamgir et al. (2007) mentioned that although regulations and hospital policies discourage recapping of conventional needles and encourage point of use disposal containers, examination of injury description reports reveals that recapping still occurs when using conventional needle. Abdel-Razik and Abdel-Rahman (2011) reported that most needle-stick injuries occurred during syringe recapping or bending after use. The present study found that the proper practice and compliance to guidelines regarding handling and disposal of sharps, had waste bags were securely fasted when $75 \%$ full at fever hospital $12 \%$ at pre-test, which increased to $(84 \%)$ at post-test and follow up. At the general hospital $63 \%$ pre-test increased to $100 \%$ at post-test and follow up. due to unavailability of proper sharps boxes, in adequate knowledge and training about handling and disposal of sharps, inadequate resources, lack of supervision and inadequate training about sharp waste-control. OSHA (2005) issued the highest number of citation category. The commonest violations were lack of a written exposure control plan, not using sharps safety devices, inadequate training, and not keeping an exposure log. A total of $63 \%$ nurses had waste bags and securely fasted at pre-test, and increased to $100 \%$ at post-test and follow up at fever hospital, they were $72 \%$ at pre-test, and increased to $94 \%$ at post-test and follow up at general hospital due to inadequate knowledge, training, and lack of supervision about handling of wastes, inadequate resources. Ferreire and Teixeira (2010) reported higher risk perception and adherence to procedures concerning waste disposal and sharps and needles handling and disposal. Kabbash et al. (2007) reported in hemodialysis units in Egypt as they reported that the environmental and administrative studied were below acceptable standards. They added that disposal of waste materials out-doors carried many risk infective agents to handling workers. The present study found significant differences between pre, post and follow up related to all items of waste management. Actual performance of nursing exposure control plan immediate action after injury, at fever hospital about (13.3\%) nursing had immediate action (injured person) at pre- program, and increased to $(93.3 \%)$ at post program and follow up and at general hospital about $(6 \%)$ nursing reported incident immediately to the department at pre-test, increased $(92.3 \%)$ at post-test and follow up. In Poland, among 314 new cases of occupational diseases among HCWs, HBV \& HCV were $42.6 \%$ of all cases (Wilczynska et al, 2005). High significant differences between pre, post and follow up related to all items related to exposure control plan immediate action after injury. Median scores of nursing staff performance (hand hygiene, personal protective equipment, injection safety, handling and disposal of sharps, waste management and 
exposure control plan) through the pre-test, post-test and follow up phase. This agreed with Petrit et al. (2014) who found that nurses must have good know-ledge before their initial training period at hospital which was a prerequisite for compliance. Also, specialized training must be given before a health care student undertook any patient procedure involving contamination or infection. There is a must to strengthen nursing curriculum on infection control, given that nurses were likely having more contact with patients than any other HCWs.

Medians were have high significant differences $(p<0.001)$, indicated significant improvement of their performance to infection control measures related blood protozoa acquired by needle-stick injury. The percentage distribution of the nursing staff total performance score regarding infection control measures related to infectious blood protozoa acquired by needle-stick injury through the program. At pre-test phase the adequate performance of nursing staff was $(46.7 \%)$ while at post-test, and follow up was $100 \%$. This agreed with Miguela et al. (2007) in Latin America who showed that course content and teacher performance met the trainees' needs and that all trainees acquired the necessary knowledge and skills. There were high significant differences (p- 0.001), indicated improvement of performance to infection control measures of blood protozoa acquired by needle-stick injury. But, no correlation was detected between knowledge and performance in pre-test $(\mathrm{p}<0.001)$, but positive correlation between nursing staff knowledge and performance in post-test and follow up. Ibrahim et al. (2011) in Menoufia University Hospital reported that lack of the compliance to infection control standards was due to lack of know-ledge of mode of infection and control; poor design of hospital unit; high work load; lack of sustainable resources and arrangements; time of contacts (daytime or night shift), and lack of training and constructive supervision. They added that efforts were needed to correct the unac- ceptable nursing performance, especially mismatching was noticed between what nursing staff know and what they actually do. But, significant positive correlation was found between knowledge. Ndikom and Onibokum (2007) reported significant positive correlation between know-ledge and practice of standard precautions Moqbel et al. (2015) in Yemen reported that planned health education program improved nurses' knowledge and practice as to infection prevention and control measures and endoscopy reprocessing at endoscopy units.

As to handling and disposal of sharps instruments: Visser et al. (2006) defined attitude as a psychological tendency that is expressed by evaluating a particular entity with some degree of favor or disfavor. So, evaluation of attitude towards certain topic can help to know the readiness of the target people to know what is new in that topic (Nabi et al, 2007). In the present study, a highly significant improvement in attitude was in all aspects. Attitude in pre-test evaluation scored (1.77 \pm .430$)$, care to blood protozoan

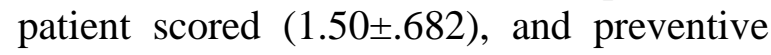

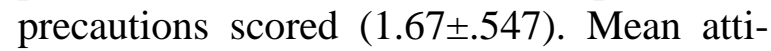
tude increased at post-test $(\mathrm{P}<0.001)$. At the general hospital attitude in pre-test, scored

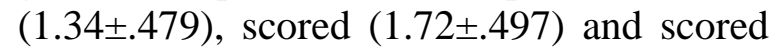

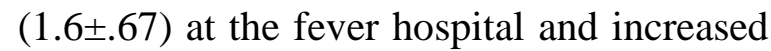
at post-test $(\mathrm{P}<0.001)$ respectively. Wood (2000) found that the highest attitude score of nurses was for taking all recommended vaccines and isolation of infected cases. Lapinski and Franklin (2001) mentioned that isolation of infected cases and valid vaccination certificate took the highest score Percentage of studied nursing staff total attitude towards the handling and disposal of sharps instrument throughout the program. Most of the nurses at the fever hospital (90\%) had negative attitude at the pre-test. at post-program, up most $(97 \%)$ had positive attitude. But, at follow up phase $(77 \%)$ had positive attitude. Nurses $(92 \%)$ had negative attitude at pre-test and $98 \%$ had positive attitude at post- test. There was high significant differ- 
ence $(\mathrm{p}<0.001)$ indicated attitude improvement. This agreed with Rabaud et al. (2000) and El-Bahnasawy and Morsy (2015) who reported the proper positive attitude toward safety health among nurses especially with vaccination. There were no correlation was detected between knowledge and attitude of nursing staff by the program phase's pre, post, and follow-up ( $\mathrm{P}>0.05)$. Fazio and Michael (2003) noticed that attitude change was related to individual characteristics, and message source characteristics specially expertise. Cialdini and Goldstein (2004) noticed that the highly educated people could change their attitude with effective message more than less educated ones.

\section{Recommendations}

Nurses employed in health care workplaces face a serious danger that may threaten their life; it is their exposure to blood and body fluids (BBF). Indeed, accidental exposure may lead to infections by blood borne pathogens, BBPs.

Lack of nurse knowledge about blood parasite infectious diseases, their way of transmission, symptoms and signs, ways of protection can negatively affect the nature and spread of these diseases among medical personnel.

No doubt, continues training programs about blood protozoa acquired by needle stick injury must be developed and provided on regular basis, this would enable the nursing staff to improve knowledge, performance and attitude about these infectious blood diseases acquired by blood transfussion as well as by the needle stick injury.

\section{References}

Abdel-Razik, S, Abd el-Rahman, S, 2011: Needle-stick injury and its relation to infection control training program among nursing staff member in Minia University Hospital. Egypt. Nurs. J. 1: 1146-47.

Adams, D, Down, S, Hicks, D, 2013: Safety: recommendations in the diabetes care setting. Br. J. Nurs. 22, 17:997-1000.

Ahmed, SM, Hassan, SA, Abd-Allah, ES, 2008: Compliance with universal precautions among nurses and laboratory technicians in Mansoura International Specialized Hospital. Egypt. J. Hosp. Med. 30:151-64.

Alamgir, M, Bidlingmaier, W, Glawe, U, Ma- rtens, J, Sharif, L. et al, 2007: Safe and Sustainable Management of Municipal Solid Waste in Khulna City of Bangladesh. $11^{\text {th }}$ Int. Waste Manag. Land-fill Symp. Cagliari, Italy.

Al-Saigul, AM, Fontaine, RE, Haddad, Q, 2000: Nosocomial malaria from contamination of a multi-dose heparin container with blood. Infect. Control Hosp. Epidemiol. 21, 5:329-30.

Alwutaib, AH, Abdulghafour, YA, Alfadhli, AK, Makboul, G, et al, 2012: Knowledge and attitude of the physicians and nurses regarding blood borne infections in primary health care, Kuwait. Greener J. Med. Sci. 2, 4:107-14

Anderson, DJ, Kirkland, KB, Mcdonald, JR, 2006: Result of a survey of work duties of 56 infection control professionals (ICPs): Are new guidelines needed for the staffing of infection control (IC) programming 207 Abstract 146. In: $16^{\text {th }}$ Ann. Soc. Healthcare Epidemiol. Chicago.

Askarian, M, Shaghaghian, S, Gillen, M, Assadian, O, 2007: Body fluid exposure in nurses of Fars Province, Southern Iran. Arch. Iranian Med. 11, 5:515-21

Ausburn, LJ, 2004: Course design elements most valued by adult learners in blended online education environment: An American perspective. Educ. Media Int. 41, 4:327-37

Australian Safety \& Compensation Council (ASCC) 2008: Occupational Exposure in Australian Nurses: Report of the Project. Available online from: www.safeworkaustralia. Gov.au/ About Safe Work Australia

Babcock, HM, Zack, JE, Garrison, T, 2004: An educational intervention to reduce ventilator associated pneumonia in an integrated health system: a comparison of effects. Chest 125,6 : 2224-31.

Baird, JK, 2000: Resurgent malaria at the millennium: control strategies in crisis. Drugs 59, 4:719-43

Baudu, A, lot, F, Abiteboul, D, Iheriteau, F, Touche, S, G et al, 2011: Pour le comite de pilotage national de la surveillance aesraisingeres suivi des accidents exposant au sang chez les professionnels de santé non immunizes et exposes au vhp,2005-2007 (France). Bull. Epidemiol. Hebdomad. 35, 36:388-91.

Hsieh, WB, Chiu, NC, Lee, CM, Huang, FY, 2006; Occupational blood and infectious body fluid exposures in a teaching hospital: a threeyear review. J. Microbiol. Immunol. Infect. 39, 4:321-7.

Burke, JP, 2003: Patient safety: Infection contr- 
ol: A problem for patient safety. N. Engl. J. Med. 348, 7:651-6

Burke. KM, Lemone, P, Brow, EL, 2007: Medical-Surgical Nursing Care. $2^{\text {nd }}$ ed. New Jersey: Person education Inc., Upper Saddle River. Canadian Center for Occupational Health \& Safety (CCOHS), 2005: Needle sticks Injuries. Available at:au/policies/pd/200/PD2007036.html Carmela, CN, Adele, M, Giuseppe, LAT, Maria, DEG, 2012: Biological Risk and Occupational Health. Indust. Hlth. 50:326-37.

CDC, 2007: Guideline for Isolation Precautions: Preventing Transmission of Infectious Agents in Healthcare Settings. Atlanta, GA, USA.

CDC, 2008: Health information for International Travel. Atlanta, GA, USA.

CDC, 2014: Prevention 1600 Clifton Rd. Atlanta, GA. 30329-4027. USA. 800-CDC-Info (800232-4636) TTY: (888) 232-9348.

Cialdini, RB, Goldstein, NJ, 2004: Social influence: Compliance and conformity. Ann. Rev. Psychol. 55:591-621

Collins, A, 2008: CDC definitions of nosocomial infections. Available online: http:// www. cdc. gov/ncidod/dhqp/nnis_pubs.html

Considine, J, Botti, M, Thomas, S, 2007: Do knowledge and experience have specific roles in triage decision-making. Acad. Emerg. Med. 14: 7226.

Cummingham, JL, 1998: Critical care orientation: A comparison of two teaching methods. J. Crit. Care 17, 5:469-75'

Dawson, SJ, 2003: The role of the infection control link nurse. J. Hosp. Infect. 54, 4:251-7

Dyson, L, Hedgecock, B, Tomkins, S, Cooke, G, 2009: Learning needs assessment for registered nurses in two large acute care hospitals in Urban New Zealand. Nurse Educ. Today 29, 8: 821-8.

El-Bahnasawy, MM, Morsy, TA, 2015: Beyond immunization: Travelers' infectious diseases. 1- Diarrhea. J. Egypt. Soc. Parasitol. 45, 1:2942.

El-Bahnasawy, MM Dabbous, HKh, Morsy, T A, 2010: Imported malaria as a threat to Egypt. J. Egypt. Soc. Parasitol. 40, 3:773-87.

El-Bahnasawy, MM, Khalil, H.H, Morsy, TA, 2011: Babesiosis in an Egyptian boy acquired from pet dog, and a general review. J. Egypt. Soc. Parasitol. 41, 1:9-108.

Fazio, RH, Michael AO, 2003: Attitudes: Foundations, Functions, and Consequences. Sage's Handbook of Social Psychology London.
Ferreira, V, Teixeira, M, 2010: Healthcare waste management practices and risk perceptions: Finding from hospitals in the Algarve region, Portugal. Waste Manag. 30:265763

Fey, MK, Miltner, RS, 2000: A CompetencyBased Orientation Program for New Graduate Nurses. Jona Lippincott Williams \& Wilkins, Inc Frankel, A, 2008: What leadership styles should senior nurses develop? Nurs. Tim.104: 35:23-4.

Galazzi, A, Rancati, S, Milos, R, 2014: A survey of accidents during the clinical rotation of students in a nursing degree program. G. Ital. Med. Lav. Ergon. 36, 1:25-31

Gershon, RR, Qureshi, KA, Pogorzelska, M, Rosen, J, Gebbie, KM, et al, 2007: Non-hospital based registered nurses and the risk of blood-borne pathogen exposure. Ind. Hlth. 45, 695704.

Goodall, J, Kmel, R, 2007: Occupational hazards to health care workers: diverse, ill- defined and not fully appreciated. Am. J. Infect Control 18:316-27

Grant, J, 2002: Learning needs assessment: Assessing the need. BMJ 324:7330.

Grayson, L, Russo, P, Ryan, K, Bellis, K, Heard, K, 2009: Hand Hygiene Australia Manual: Australian Commission for Safety and Quality in Healthcare and WHO

Guerra, CM, Ramos, MP, Penna, VZ, Goto, J M, Santi, LQ, et al, 2010: Perceptions and attitudes of the professional staff concerning infection surveillance and control programs in Brazilian hospitals. Am. J. Infect. Control 3, 8: 59-62.

Hamid, MZA, Aziz, NA, Anita, AR, Norlijah, O, 2010: Knowledge of blood-borne infectious diseases and the practice of universal precautions amongst health-care workers in a tertiary hospital in Malaysia. Southeast Asian J. Trop. Med. Publ. Hlth. 41, 5:1192-9.

Hanafi. M, Mohamed. A, Shawki, M, 2011: Needle sticks injuries among health care workers of University of Alexandria hospitals. Eastern Mediterr. Hlth. J. 17, 1:17-27.

Herwaldt, BL, Juranek, DD, 1993: Laboratory acquired malaria, leishmaniasis, trypanosomiasis, and toxoplasmosis. Am. J. Trop. Med. Hyg. 48, 3:313-23.

Ibrahim, YS, Said, AM, Hamdy, GK, 2011: Assessment of infection control practices in neonatal intensive care unit. Egypt. J. Comm. Med. 29, 4:27-45

Idang, NO, Mfon, E, Faith, F, Margret, IA, 2014: The practice of hand washing for the pre- 
paration of nosocomial infections among nurses in general hospital Ikot Ekpene. Akwa Ib-orn State, Nigeria. Arch. Appl. Sci. Res. 6, 1:97-101 Itrat, A, Khan, A, Javaid, S, Kamal, M, Khan, H, et al, 2009: Knowledge, awareness and practices regarding dengue fever among the aduIt population of dengue hit cosmopolitan. PLOS One 3, 7:2620.

Kabbash, I, El-Sayed, N, Al-Nawawy, A, Abou Salem, M, El-Deek, B, et al, 2007: Risk perception and precautions taken by health care workers for HIV infection in hemodialysis units in Egypt. East. Mediter. Hlth. J. 13, 2:392-407.

Kaye, A, 2011: Toxoplasmosis: diagnosis, treatment, and prevention in congenitally exposed infants. J. Pediatr. Hlth. Care 25, 6:355-64.

Ker, K, Edwards, PJ, Felix, LM, Blackhall, K, Roberts, I, 2010: Caffeine for the prevention of injuries and errors in shift workers. The Cochrane Database of Systematic Reviews 5: CD008508.

Knot, I, 2010: Eye of the Needle: United Kingdom Surveillance of Significant Occupational Exposures to Blood borne Viruses in Healthcare Workers, Health Protection Agency

Krafts, K, Hempelmann, E, Oleksyn, BJ, 2011: Research of the malarial parasite: Biographical sketches of the blood stain contributors. Parasitol. Res. 109, 3:521-9.

Lapinski, MK, Franklin, JB, 2001: Modeling the ego-defensive function of attitudes. Comm. Monographs 68, 3:314-24

Lau, JT, Fung KS, Wong TW, 2004: SARS transmission among hospital workers in Hong Kong. Emer. Infect. Dis. 10, 2:280-6.

Lipscomb, J, Sokas, R, McPhaul, K, Scharf, B, Barker, P, et al, 2009: Occupational blood exposure among unlicensed home care workers and home care registered nurses: are they protected? Am. J. Ind. Med. 52, 7:563-70.

Luz, ZMP, et al, 2005: Evaluation of a pamphlet on visceral leishmaniasis Cad. Saúde Públ. Rio de Janeiro, 21, 2:606-21.

Lynore, D, DeSilets, ED, 2007: Needs Assessment: An array of possibilities. J. Conti. Educ. Nursing 38, 3:107-14

McGowan, JE, Tenover, FC, 2004: Confronting bacterial resistance in healthcare settings: A crucial role for microbiologists Nat. Rev. Microbial. 2, 3:251-8.

Miguela, AC, Gabriela, M, McCullers, J, Wilfrido, A, Rafael, C, et al, 2007: Planning and implementation of an infection control training program for healthcare providers in Latin America. Infect. Cont. Hosp. Epidemiol. 28, 12:132833.

MOHP, 2004: Egyptian Vital Statistics, Ministry of Health and Population :http://www. mohp. gov.eg.

Molyneux, DH, 2003: Climate change and tropical disease: Common themes in changing vector-borne disease scenarios, Trans. R. Soc. Trop. Med. Hyg. 2:129-32

Moqbel, AA, Shebl, AM, Soliman, HM, 2015: Effectiveness of planned health education program on nurses' knowledge and practice for preventing infection in gastrointestinal endoscopy units at major hospitals in Yemen. J. Nurs. Hlth. Sci. 4, 6:39-47 www.iosrjournals.org

Morsy, TA, 2013: Cutaneous leishmaniasis predisposing to human skin cancer: Forty years local and regional studies. J. Egypt. Soc. Parasitol. 43, 3:29-48.

Nabi, RL, Moyer-Guse, E, Byrne, S, 2007: All joking aside: A serious investigation into the persuasive effect of funny social issue messages. Comm. Monographs, 74, 29-54.

National Institute for Occupational Safety and Health (NIOSH), 2012: Stop Sticks. National Institute for Occupational Safety and Health: 31-1. Publication No. 2008-101

National Occupational Health and Safety Commission (NOHSC), 2010: National Code of Practice for the Control of Work-Related Exposure to Hepatitis and HIV (Blood-Borne) Viruses. $2^{\text {nd }}$ ed.: Australian Government National Occupational Health \& Safety Commission.

Ndikom, C, Onibokun, A, 2007: Knowledge and behavior of nurse/midwives in the prevention of vertical transmission of HIV in Owerri, Imo State, Nigeria: a cross-sectional study. BMC Nursing 6: 9doi:10.1186/1472-6955-6-9

NIOSH, 2010: Occupational Hazards in Home Health-care: Department of Health and Human Services; CDC. E-mail:cdcinfo@cdc.gov

Occupational Safety and Health Administration (OSHA), 2001: Department of Labor: Occupational exposure to blood borne pathogens: Final rule. 29 CFR Parts 1910:1030

Occupational Safety and Health Administration (OSHA) 2005: Standard Cited for SIC 2008; all sizes; Federal. OSHA, Department of Labor, 1-6-0006, Electronic Citation.

Omar, AA, Abdo, NM, Salama, MF, Al-Mousa, HH, 2015: Occupational injuries prone to infectious risks amongst healthcare personnel in 
Kuwait: a retrospective study. Med. Princ. Pract. 24, 2:123-8.

Perry, C, 2007: Infection Prevention and Control. Blackwell, Oxford

Petrit, B, Migena, G, Indrit, B, 2014: Knowledge and source of information among health care students on nosocomial infections. Int. J. Human Soc. Sci. Educ. 1, 7:46-51

Pyrek, KM, 2001: Infection disease surveillance goes high tech. new developments include syndrome based surveillance and nationwide electronic system. Infect. Cont. Today 21:17-24.

Rabaud, C, Agnes, Z, Marie, M, Francoise, B, Didier, D, et al, 2000: Occupational exposure to blood: Search for a relation between personality and behavior. Infect. Cont. Hosp. Epidemiol. 21, 9: 564-574

Rutala, WA, Weber, DJ, 2004: Disinfection and sterilization in health care facilities: what clinicians need to know. Clin. Infect. Dis. 39, 5: 702-9

Saleh, AMA, Adam, SM, Ibrahim, AMA, Morsy, TA, 2017: A training program for nursing staff regarding blood parasites acquired by needle-stick injury in a military hospital. J. Egypt. Soc. Parasitol. 47, 1:65-80.

Sausa, DA, 2006: How the Brain Learns. 3rd edition; California: Car-win Press.

Shiva, F, Sanaei, A, Shamshiri, AR, Ghotbi, F, 2011: Survey of need stick injuries in pediatric health personnel of 5 university hospitals in Tehran. J. Pakis. Med. Assoc. 61:127-31

Singru, A, Banerjee, A, 2008: Occupational exposure to blood and body fluids among health care workers in a teaching hospital in Mumbai, India. Indian J. Comm. Med. 33, 1:26-30

Singru, A, Banerjee, A, 2008: Occupational exposure to blood and body fluids among health care workers in a teaching hospital in Mumbai, India. Indian J. Comm. Med. 33, 1:26-30

Srinivasan, A, Beek, C, Buckley, T, 2002: The ability of hospital ventilation systems to filter Aspergillus and other fungi following a building implosion. Infect. Control Hosp. Epidemiol. 23, 9:520-4

Statutory Instrument, 2013: The Health and Safety (Sharp Instruments in Healthcare) Regulations 013 No. 645. Printed and published in the UK by the Stationery Office Limited under the authority and superintendence of Carol Tullo, Controller of Her Majesty's Stationery Office and Queen's Printer of Acts of Parliament.
Sudan, V, Jaiswal AK, Shanker, D, 2013: Re cent trends in the diagnosis of toxoplasmosis. Clin. Rev. Opin. 5, 2:11-7

Taylor, C, Lillis, C, Lemon, P, 2001: Fundamental of Nursing: The Art and Science of Nursing Care. $4^{\text {th }}$ ed. New York: Lippincott, Williams and Wilkins Company.

Theresa, G, Jonathan, D, Jacob, K, Somashekhar, N, Norman, Z, et al, 2013: Controlling health hazards to hospital workers: A reference guide 2013, Baywood Publishing. New solutions 23:S1-167, http:/baywood.com

Thomas, WJ, Murray, JR, 2009: The incidence and reporting rates of needle-stick injury amongst UK surgeons. Ann. Roy. Coll. Surg. England 91, 1:12-7

Tweed, C, Tweed, M, 2008: Intensive care nurses' knowledge of pressure ulcers: Development of an assessment tool and effect of an educational program. Am. J. Crit. Care 17:338-46.

Vaz, K, McGrowder, D, Lindo, RA, Gordon, L, Brown, P, et al, 2010: Knowledge, Awareness and compliance with universal precautions among health care workers at the university hospital of the West Indies, Jamaica Int. J. Occup. Environ. Med. 1, 4:171-81.

Vij, A, Williamson, S, Gupta, S, 2001: Knowledge and practice of nursing staff towards infection control measures in a tertiary care hospital. J. Acad. Hosp. Admin. 13:2-8.

Visser, Penny S., Bizer, George Y, Krosnick, A, 2006: Exploring the latent structure of strengh-related attitude attributes. Adv. Exp. Soc. Psychol. 38:1-67

While, A, Ullman, R, Forbes, A, 2007: Development and validation of a learning needs assessment scale: a continuing professional education tool for multiple sclerosis specialist nurses. J. Clin. Nurs. 16. 6:1099-108.

WHO, 2002: Prevention of Hospital-Acquired Infection: Practical Guide, $2^{\text {nd }}$ ed., Healthcare Settings.http://www.cdc.gov/ncidod/dhqp/pdf/.

WHO, 2009: Guidelines on Hand Hygiene in Health Care In: first Global patient Safety Challenge clean care is safer Care, Geneva Wilczyn, SKA, Dabrowska, N, Szymczak, W, 2005: Occupational disease in Poland. Med. Prevent. 57:225-34.

Wood, W, 2000: Attitude change: Persuasion and social influence. Ann. Rev. Psychol. 51: 539-70. 